\title{
Fasting increases iron export by modulating ferroportin 1 expression through the Ghrelin/GHSR1a/MAPK pathway in the liver
}

\section{Qianqian Luo}

Nantong University

Jianan $\mathrm{Hu}$

Nantong University

Guang Yang

Hubei University for Nationalities School of Medical Science

Xiaoyu Yuan

Nantong University

Zhongping Chen

Nantong University

\section{Dan Wang}

Nantong University

Yapeng Lu

Nantong University

Li Zhu

Nantong University

Guohua Wang ( $\nabla$ wgh036@hotmail.com )

Nantong University https://orcid.org/0000-0002-4810-8534

\section{Research}

Keywords: Fasting, Ghrelin, Iron-related proteins, Ferroportin (Fpn1), MAPK signaling pathway

Posted Date: January 10th, 2020

DOI: https://doi.org/10.21203/rs.2.20524/v1

License: (c) (1) This work is licensed under a Creative Commons Attribution 4.0 International License. Read Full License 


\section{Abstract}

Background: The liver is the metabolic organ considered to contribute the most to maintaining body iron homeostasis and is a regulator of body adaptation to fasting. Our previous studies implied a negative relationship between iron and ghrelin in both mice and humans and indicated that ghrelin was able to increase ferroportin 1 (Fpn1) expression in the spleen and macrophages through the GHSR/MAPK pathway. However, it remains to be explored whether fasting or ghrelin has a functional effect on iron homeostasis in the liver.

Methods: In this study, we examined the roles of fasting and ghrelin in modulating the protein expression of Fpn1, transferrin receptor 1 (TfR1), and ferritin light chain (Ft-L), as well as the mRNA expression of ghrelin, hepcidin, ghrelin 0-acyltransferase (GOAT) and growth hormone secretagogue receptor 1 alpha (GHSR1a) in mouse liver and cultured hepatocytes.

Results: Our in vivo results suggested that fasting significantly upregulated the mRNA expression of ghrelin, GOAT and GHSR1a as well as the protein levels of ghrelin, Fpn1 and Ft-L, but not TfR1, in mouse liver. Meanwhile, in cultured hepatocytes, ghrelin significantly increased the protein expression of Fpn1 but not Ft-L and TfR1 and significantly enhanced ERK phosphorylation. Furthermore, the pretreatment of cultured hepatocytes with either a pERK inhibitor or a GHSR1a antagonist abolished the effects of ghrelin on Fpn1 expression and ERK phosphorylation.

Conclusions: Our findings confirmed that fasting increases iron export in the liver by upregulating Fpn1 expression through the ghrelin/GHSR1a/MAPK signaling pathway.

\section{Background}

The liver is considered the central organ in maintaining body iron homeostasis because it is not only a major iron storage compartment but also the site where hepcidin, the key peptide that controls iron export and regulates iron metabolism, is synthesized [1]. In addition, the liver is considered a regulator of body adaptation to fasting [2]. During fasting, profound changes occur in the liver to reduce energy use and limit catabolism, including changes in hormones such as ghrelin [3]. Ghrelin, which is mainly produced and secreted by P/D1 cells of the stomach and contains 28 amino acids [4], can be increased during energy restriction and fasting and may affect appetite and eating behaviors [5]. This hormone functions in the brain and regulates food consumption and glucose metabolism; therefore, it is related to body weight changes and fattiness [6-9]. It is also observed to activate the orexigenic neural circuits and modulate the systemic metabolism $[8,10]$, and it also functions in central and peripheral tissues, promoting appetite, enhancing gastrointestinal tract motility, and exerting anti-inflammatory effects, among others. Ghrelin has two forms and becomes active only after being acylated by ghrelin 0acyltransferase (GOAT), which catalyzes the attachment of the eight-carbon fatty acid octanoyl to the Ser3 side chain of the peptide ghrelin [11-13]. 
Ghrelin enhances appetite and promotes food consumption during starvation [14-16]. Poor appetite is one of the obvious clinical characteristics of iron deficiency anemia (IDA)[17] and perpetuates a state of starvation $[18,19]$. These characteristics were consistent with the finding that IDA might be attributable to decreased ghrelin levels [20,21], which suggested potential correlations between ghrelin and changes in iron metabolism. An investigation in prepubertal children also observed significantly lower iron contents and ghrelin levels in IDA groups than in healthy controls [22]. Another study on the changes of iron and ghrelin in various different phases of IDA (hypoferritinemia/iron deficiency/iron deficiency anemia) in children also confirmed that both iron content and ghrelin levels are decreased in the plasma and reached their minimum levels in the last stage of IDA [23].

An investigation by Dogan et al. suggested that while children suffering from IDA showed lower levels of serum hepcidin and ghrelin than healthy children, iron treatment significantly elevated the hepcidin and ghrelin levels in the serum of IDA children [24]. In our previous study, a statistically significant negative correlation was also found between iron levels and ghrelin in the serum [25]. Based on these findings, we hypothesized that ghrelin may modulate the balance of iron homeostasis under physiological conditions. In this study, we examined the effects of fasting and of ghrelin on the protein or mRNA expression of ghrelin, GHSR1a, GOAT, ferroportin 1 (Fpn1), transferrin receptor 1 (TfR1) and ferritin light chain (Ft-L) in the liver and/or cultured hepatocytes. Moreover, we examined the roles of GHSR1 $a$ antagonist and phosphorylated-extracellular regulated protein kinase (pERK) inhibitor in the expression of Fpn1 and pERK in cultured hepatocytes. Our results demonstrated that fasting or ghrelin was able to increase Fpn1 expression via the ghrelin/GHSR1a/MAPK signaling pathway in the liver and cultured hepatocytes.

\section{Materials And Methods}

\section{Animals and Materials}

Unless otherwise stated, all chemicals and reagents used in this study were purchased from Sigma (St. Louis, MO, USA). Ghrelin was obtained from BioVision (4990 - 1000, CA, USA). All mice were supplied by the animal experimental center of Nantong University. All mice used were housed in stainless steel cages with $55 \%-60 \%$ relative humidity at $21 \pm 2{ }^{\circ} \mathrm{C}$ with alternating 12 -hr periods of light and dark. All animal handling procedures were conducted in accordance with guidelines approved by the Laboratory Animal Ethics Committee of Nantong University.

\section{Animal Fasting Treatment}

Eight-week-old male C57BL/6J mice were assigned randomly by weight to groups and were fasted for 0 , 6 , or $24 \mathrm{hr}$ prior to tissue samples collection. The mice were anesthetized intraperitoneally with $1 \%$ pentobarbital sodium ( $40 \mathrm{mg} / \mathrm{kg}$ body weight) and received myocardial perfusion using phosphate buffered saline (PBS), after which liver tissues were collected for measurements.

\section{Isolation and Culture of Mouse Hepatocytes}


Cultured hepatocytes were obtained from male C57BL/6J mice by a two-step collagenase IV perfusion procedure [26]. Livers from C57BL/6 mice were first perfused with preperfusion buffer via the portal vein for $15 \mathrm{~min}$, followed by $0.1 \mathrm{mg} / \mathrm{mL}$ collagenase IV dissolved in enzyme buffer at $37^{\circ} \mathrm{C}$ until the liver capsule was incised. After a sufficient amount of time (approximately $20 \mathrm{~min}$ ) for liver tissue digestion, the thick fibrous connective tissues were discarded. The suspension was filtered and centrifuged to collect the hepatocytes. Then, the hepatocytes were seeded in six-well plates $\left(\sim 2 \times 10^{6}\right.$ cells $/$ well $)$ and cultured in Dulbecco's modified Eagle's medium with $10 \%$ fetal bovine serum, penicillin (100 units $/ \mathrm{ml})$, and streptomycin $(100 \mu \mathrm{g} / \mathrm{ml})$ and cultured at $37^{\circ} \mathrm{C}$ in a $5 \% \mathrm{CO} 2$ incubator. For ghrelin treatment, cultured hepatocytes were incubated with ghrelin (100 nM) or PBS (control) for $0.5-3 \mathrm{hr}$, and then the cells were washed with PBS and lysed to obtain RNA or proteins.

\section{Total RNA Extraction and Semiquantitative and Quantitative Real-time PCR (q-PCR)}

Total RNA was isolated and extracted from tissues and cells were using the Trizol extraction method. A total of $1 \propto \mathrm{g}$ of RNA was reverse transcribed by the HiScript II Q RT SuperMix for qPCR (+ gDNA wiper) Kit according to the manufacturer's instructions to obtain CDNA. q-PCR was performed using the FastStart Universal SYBR Green Master Mix (Vazyme Biotech Co., Ltd., China) in an LC96 instrument (Roche, Switzerland). The primer sequences (Sangon Biological Engineering Technology \& Services Co., Ltd.,Shanghai, China)[25] used in this study are listed below (Table 1). The CT values of each target gene were normalized to those of $\beta$-actin in each group. Finally, the relative expression of mRNA was determined using the $2^{-\triangle \Delta C T}$ method.

Table 1

Primer Sequences

\begin{tabular}{|c|c|}
\hline Name (mouse species) & Primers used in PCR (from $5^{\prime}$ to $3^{\prime}$ ) \\
\hline ghrelin forward & TCCAAGAAGCCACCAGCTAA \\
\hline ghrelin reverse & AACATCGAAGGGAGCATTGA \\
\hline GHSR1 a forward & CTATCCAGCATGGCCTTCTC \\
\hline GHSR1a reverse & AAGACGCTCGACACCCATAC \\
\hline GOAT forward & ATTTGTGAAGGGAAGGTGGAG \\
\hline $\begin{array}{l}\text { GOAT reverse } \\
\text { hepcidin forward } \\
\text { hepcidin reverse } \\
\beta \text {-actin forward } \\
\beta \text {-actin reverse }\end{array}$ & $\begin{array}{l}\text { CAGGAGAGCAGGGAAAAAGAG } \\
\text { GCACCACCTATCTCCATCAACA } \\
\text { TTCTTCCCCGTGCAAAGG } \\
\text { AAATCGTGCGTGACATCAAAGA } \\
\text { GCCATCTCCTGCTCGAAGTC }\end{array}$ \\
\hline
\end{tabular}

\section{Western Blot Analysis}


Proteins from cells or tissue were extracted and homogenized with RIPA lysis buffer (Beyotime, PRC) and sonicated by a sonifier [27]. The BCA (Pierce, Rockford) detection method was employed to determine the protein contents. A sample containing $30 \propto \mathrm{g}$ of protein was loaded and run in each well of SDS-PAGE gels. The membranes were incubated with primary antibodies (1:1000) for TfR1 (Life Technology), Fpn1 (Novus), Ferritin-L (Proteintech), pERK against 42/44 (Cell Signaling Technology), ERK (Cell Signaling Technology), ghrelin (Abcam), and GHSR1 a (Abcam) at $4{ }^{\circ} \mathrm{C}$ overnight. Blots were then performed with a secondary antibody of goat anti-rabbit or anti-mouse IRDye $800 \mathrm{CW}$ at 1:10000 dilution (Li-Cor, Lincoln Co., Ltd., USA) at room temperature for $1 \mathrm{hr}$. The gray values of the specific blots were scanned and analyzed with ImageJ software. $\beta$-Actin monoclonal antibody (Sigma, 1:10000) was used as a loading control.

\section{Immunofluorescence}

Liver samples were fixed using $10 \%$ neutral formaldehyde and embedded in paraffin. The specimens were sectioned at a thickness of $5 \mu \mathrm{m}$, then blocked for $2 \mathrm{hr}$ in blocking TBS buffer containing $3 \%$ bovine serum albumin (BSA), and finally incubated with GHSR1a primary antibody $(1: 400)$ at $4{ }^{\circ} \mathrm{C}$ overnight. Immunoreactivity was examined by incubation with Alexa Fluor 488-conjugated secondary antibody at 1:400 (Invitrogen) at room temperature for $1 \mathrm{hr}$. Finally, $5 \mathrm{mg} / \mathrm{ml}$ Hoechst 33342 was added for nuclei staining for $15 \mathrm{~min}$. Specimens were mounted with 50\% glycerin, and the fluorescence signals were detected using an SP8 confocal laser scanning microscope (Leica, Germany).

\section{Immunohistochemistry}

Liver samples were fixed with $10 \%$ neutral formaldehyde and embedded in paraffin. The specimens were sectioned at a thickness of $5 \mu \mathrm{m}$ and then incubated at $58^{\circ} \mathrm{C}$ for $3 \mathrm{hr}$ followed by xylene treatment for dewaxing, hydrated through an alcohol gradient, and washed with PBS. A microwave was used to repair the antigens at $650 \mathrm{~W}$ for $20 \mathrm{~min}$, and the samples were then cooled to room temperature. Then, the cells were exposed to $3 \% \mathrm{H}_{2} \mathrm{O}_{2}$ and normal goat serum for 10 min to block the activity of endogenous catalase and nonspecific binding. Finally, the slice specimens were incubated with ghrelin antibody (Cell Signaling Technology, 1:250) overnight at $4{ }^{\circ} \mathrm{C}$. Ghrelin immunoreactions were detected with the enhanced biotinstreptavidin immunoperoxidase technique. Diaminobenzidine was used as the chromogenic substrate, followed by hematoxylin counterstaining. Five slices of each group were chosen for determining the distribution and expression of ghrelin in the liver under a light microscope. Five visual fields were selected randomly in each slice for statistical analysis by ImageJ software (Media Cybernetics, Silver Spring, USA).

\section{Statistical Analysis}

Statistical analyses were executed with GraphPad Prism 7.0 software. All the data are presented as the mean \pm SEM. The variation between the means in each group was analyzed by one-way analysis of variance (ANOVA), and Tukey's post hoc test was then performed for multiple comparisons. A probability value of $p<0.05$ was considered statistically significant. 


\section{Results}

\section{GHSR1 a was expressed in the mouse liver and hepatocytes}

As a G-protein-coupled receptor, GHSR is present mainly existed in the hypothalamus and pituitary $[9,28]$. Two isoforms of GHSR have been reported [29], GHSR1 a [30, 31] and GHSR1 $\beta$ [32, 33]. However, GHSR1a is responsible for ghrelin-induced endocrine effects and some nonendocrine effects. Here, we first examined whether GHSR1a is expressed in mouse liver and cultured hepatocytes. The results of q-PCR and Western blot analyses both confirmed that the liver (Fig. 1, A and B) and cultured hepatocytes (Fig. 1, $\mathrm{C}$ and D) expressed GHSR1a mRNA and protein, although at lower levels than the hypothalamus.

\section{Fasting induced ghrelin, GHSR1a, and GOAT mRNA expression in the liver}

To investigate whether and how fasting affects the ghrelin/GHSR system, mice were fasted for 0,6 or 24 $\mathrm{hr}$, and the livers were collected to measure the expression of ghrelin, GHSR1 a, GOAT and hepcidin (Fig. 2, A-D). The q-PCR results demonstrated that ghrelin (Fig. 2A) and GOAT mRNA (Fig. 2C) were significantly increased after fasting. Compared with the control group, the mRNA expression of ghrelin, GOAT and GHSR1a (Fig. 2B) all increased significantly after fasting for $24 \mathrm{hr}$. The Western blot results also suggested that ghrelin protein expression in the liver was increased after fasting for 6 and $24 \mathrm{hr}$ (Fig. 3, A and B). Furthermore, immunohistochemistry analysis showed that ghrelin protein was mainly expressed around the veins in the liver (Fig. 3C). In addition, GSHR1a, which was mainly located on the membrane, was also increased in the liver after $24 \mathrm{hr}$ of fasting (Fig. 3D). These results confirmed that although ghrelin is mainly expressed in the stomach, it may also be expressed in other tissues, which was consistent with the results in the previous study [34].

Fasting or Ghrelin Induced Fpn1 and pERK Expression in both the Liver and Cultured Hepatocytes

To determine whether fasting or ghrelin treatment affects the iron-related proteins in the liver or cultured hepatocytes, we then explored the role of fasting or ghrelin treatment in the expression of the three pivotal proteins involved in the mediation of cellular iron related proteins, namely, Fpn1, TfR1, and Ft-L. The Western blot results demonstrated that the expression levels of Ft-L (Fig. 4, A and B; E and F) and Fpn1 (Fig. 4, A and C; E and G) in mouse liver were increased after fasting, while the TfR1 protein levels remained unchanged (Fig. 4, A and D; E and H). Western blot analysis also demonstrated that $24 \mathrm{hr}$ of fasting significantly increased ERK phosphorylation, while $6 \mathrm{hr}$ of fasting failed to induce any change (Fig. 5). Meanwhile, in vitro treatment of cultured hepatocytes with $10^{-7} \mathrm{M}$ ghrelin for $0.5 \mathrm{hr}$ or $1 \mathrm{hr}$ also induced significant increases in Fpn1 expression (Fig. 6, A and D) and ERK phosphorylation (Fig. 6, B and F). However, the expression of Ft-L (Fig. 6, A and C) and TfR1 (Fig. 6, A and E) in cultured hepatocytes treated with ghrelin did not change at any time point tested. 
Ghrelin-induced Increases in ERK Phosphorylation and Fpn1 Expression could be Suppressed by GHSR1a Antagonist or MAPK Signaling Pathway Inhibitor

To clarify the possible mechanisms by which fasting and ghrelin regulate Fpn1 expression, we further studied the effects of a GHSR1 $a$ antagonist (D-(lys-3)-GHRP-6) and a pERK inhibitor (U0126) on the phosphorylation of ERK and the expression of Fpn1 and Ft-L. Cultured hepatocytes were pretreated with D-(lys-3)-GHRP-6 at $100 \mathrm{nM}$ or U0126 at $10 \propto \mathrm{M}$ for $1 \mathrm{hr}$, followed by $10^{-7} \mathrm{M}$ ghrelin. The results indicated that D-(lys-3)-GHRP-6 significantly inhibited the ghrelin-stimulated upregulation of both pERK (Fig. 7, A and B) and Fpn1 (Fig. 7, C and D) expression but did not change Ft-L expression (Fig. 7, C and E). U0126 also suppressed ghrelin-induced increases in both pERK (Fig. 7, F and G) and Fpn1 (Fig. 7, H and I) expression in cultured hepatocytes, although there were no differences in the expression of Ft-L or TfR1 (Fig. 7, $\mathrm{H}$ and $\mathrm{J}$ ).

\section{Discussion}

Our previous study confirmed that fasting or ghrelin upregulates Fpn1 expression in both the spleen and cultured macrophages through the ghrelin/GHSR/MAPK signaling pathway. Here, we investigated whether ghrelin also influences iron homeostasis in the liver, which is the key tissue for iron storage and regulation under physiological conditions [35]. Therefore, fasting- or ghrelin-induced changes in ironrelated proteins were determined in both the liver and cultured hepatocytes.

Several primary iron metabolism-related proteins are expressed in the liver and hepatocytes, including Fpn1, TfR1 and ferritin (Ft). TfR1 is an important receptor that contributes to cellular iron uptake. Fpn1 is the only distinct cellular iron exporter known to date. There are two isoforms of $\mathrm{Ft}$, both responsible for iron storage but with different functions: Ft heavy chains $(\mathrm{Ft}-\mathrm{H})$ are associated with iron utilization, while Ft light chains (Ft-L) are more related to cellular iron storage [36]. In this study, Fpn1 and TfR1 were investigated as markers of changes in iron uptake and release, while Ft-L was examined as an iron content marker in the liver/hepatocytes.

In our study, we observed that 6 or $24 \mathrm{hr}$ of fasting significantly upregulated the mRNA expression of ghrelin, GHSR1a, and GOAT as well as the protein levels of Fpn1 and Ft-L in mouse liver. However, TfR1 expression increased after fasting for $6 \mathrm{hr}$ and decreased after $24 \mathrm{hr}$. The increases in Ft-L and Fpn1 expression suggested that fasting enhanced both iron storage and iron export in the liver. Fpn1 is a hepcidin receptor in the membrane, and the hepcidin/Fpn1 complex was first formed and then internalized into the cell and further degraded; therefore, the amount of Fpn1 protein decreased [37, 38]. However, there were no changes in hepcidin mRNA after fasting at any time point, suggesting that hepcidin may not play a prominent regulatory role in liver Fpn1 expression under fasting conditions.

As ghrelin expression increased and was mainly distributed around the veins, and the membrane-bound receptor GSHR1a also increased in the liver after fasting for $24 \mathrm{hr}$, we hypothesized that the effect of fasting on Fpn1 and Ft-L expression in the liver might be regulated by the binding and activation of the 
ghrelin/GHSR1a system. To determine whether these changes in iron metabolism related proteins were induced by the activation of GHSR1a in the liver by ghrelin, primary cultured hepatocytes were pretreated with GHSR1a inhibitor, and the protein expression levels of Fpn1, Ft-L, and TfR1 were examined. Treatment with ghrelin for 0.5 or $1 \mathrm{hr}$ showed a significant increase in Fpn1 expression in cultured hepatocytes. However, ghrelin failed to impact TfR1 or Ft-L expression. Furthermore, ghrelin-induced Fpn1 upregulation was suppressed by the GHSR1a antagonist D-(lys-3)-GHRP-6. These findings proved the involvement of the ghrelin/GHSR1a pathway in the regulation of Fpn1 expression in cultured hepatocytes.

ERK is a protein-serine/threonine kinase that can activate nuclear transcription factors and is involved in cell proliferation, differentiation and cell death [39-42]. It has been confirmed that the proliferative role of ghrelin is related to the activation of its downstream MAPK signaling cascade in multiple types of cells $[43,44]$. Our previous investigation also suggested that Fpn1 expression increased after ERK phosphorylation in the spleen/macrophages [25]. To determine whether ghrelin also increases the expression of Fpn1 through the GHSR1a/MAPK signaling pathway in cultured hepatocytes, we explored the role of ghrelin in ERK phosphorylation in the presence or absence of a MAPK signaling pathway inhibitor (U0126). The results showed that ERK phosphorylation in cultured hepatocytes was significantly enhanced after ghrelin treatment for $1 \mathrm{hr}$, while pretreatment with the pERK inhibitor U0126 suppressed the positive role of ghrelin in the expression of Fpn1 and phosphorylation of ERK. Together with the identification results from PCR and Western blot analyses showing that GHSR1a is expressed in the liver and cultured hepatocytes, all of these results confirm the hypothesis that ghrelin increases Fpn1 expression through the GHSR/MAPK signaling pathway in the liver/hepatocytes. In summary, we confirmed that ghrelin significantly affects iron homeostasis in mouse liver by modulating iron-regulating proteins, as fasting or ghrelin upregulated Fpn1 expression via activation of the GHSR/MAPK signaling pathway. However, the reason that fasting and ghrelin do not affect TfR1 expression in the spleen and liver both in vivo and in vitro remains to be investigated further.

\section{Declarations}

\section{Abbreviations}

Ferroportin 1, Fpn1; Transferrin receptor 1, TfR1; Ferritin-L, Ft-L; Ghrelin O-acyltransferase, GOAT; Growth hormone secretagogue receptor 1a, GHSR1a; Mitogen-activated protein kinase, MAPK; Extracellular regulated protein kinase, ERK

\section{Acknowledgments}

Not applicable. 


\section{Authors' contributions}

G.H.W. and L.Z. conceived, organized, and supervised the work; Q.Q.L., J.N.H., G.Y. performed the experiments; X.Y.Y., Z.P.C., D.W. and Y.P.L. contributed to the analysis of data; Q.Q.L. and G.H.W. prepared, wrote and revised the manuscript.

\section{Availability of data and materials}

All original data are available upon request.

\section{Funding}

This study was founded by the Natural Science Foundation of China (Grants 81873924, 81471257 and 31300973); Open Cooperation Program from Key Laboratory of Extreme Environmental Medicine, Ministry of Education (KL2019GY011); Natural Science Foundation of Jiangsu Province in China (Grant BK20161283), and also sponsored by Nantong Science and Technology Project (MS12018030, MS12018048).

\section{Ethics approval and consent to participate}

All animal handling procedures were conducted in accordance with guidelines approved by the Laboratory Animal Ethics Committee of Nantong University.

\section{Consent for publication}

Not applicable.

\section{Competing interests}

We declare that we have no conflicts of interest.

\section{References}

1. 
Sikorska K, Bernat A, Wroblewska A. Molecular pathogenesis and clinical consequences of iron overload in liver cirrhosis. Hepatobiliary Pancreat Dis Int. 2016;15:461-79.

2.

Rommelaere S, Millet V, Vu Manh TP, Gensollen T, Andreoletti P, Cherkaoui-Malki M, Bourges C, Escaliere B, Du X, Xia Y, et al. Sox17 regulates liver lipid metabolism and adaptation to fasting. PLoS One. 2014;9:e104925.

3.

de Vries EM, Eggels L, van Beeren HC, Ackermans MT, Kalsbeek A, Fliers E, Boelen A. Fasting-induced changes in hepatic thyroid hormone metabolism in male rats are independent of autonomic nervous input to the liver. Endocrinology. 2014;155:5033-41.

4.

Kojima M, Hosoda H, Date Y, Nakazato M, Matsuo H, Kangawa K. Ghrelin is a growth-hormone-releasing acylated peptide from stomach. Nature. 1999;402:656-60.

5 .

Goldstone AP, Prechtl CG, Scholtz S, Miras AD, Chhina N, Durighel G, Deliran SS, Beckmann C, Ghatei MA, Ashby DR, et al. Ghrelin mimics fasting to enhance human hedonic, orbitofrontal cortex, and hippocampal responses to food. Am J Clin Nutr. 2014;99:1319-30.

6.

Patterson M, Bloom SR, Gardiner JV. Ghrelin and appetite control in humans-potential application in the treatment of obesity. Peptides. 2011;32:2290-4.

7.

Davies JS, Kotokorpi P, Eccles SR, Barnes SK, Tokarczuk PF, Allen SK, Whitworth HS, Guschina IA, Evans BA, Mode A, et al. Ghrelin induces abdominal obesity via GHS-R-dependent lipid retention. Mol Endocrinol. 2009;23:914-24.

8.

Lv Y, Liang T, Wang G, Li Z. Ghrelin, a gastrointestinal hormone, regulates energy balance and lipid metabolism. Biosci Rep 2018, 38.

9.

Castaneda TR, Tong J, Datta R, Culler M, Tschop MH. Ghrelin in the regulation of body weight and metabolism. Front Neuroendocrinol. 2010;31:44-60.

10.

Wortley KE, Anderson KD, Garcia K, Murray JD, Malinova L, Liu R, Moncrieffe M, Thabet K, Cox HJ, Yancopoulos GD, et al. Genetic deletion of ghrelin does not decrease food intake but influences metabolic fuel preference. Proc Natl Acad Sci U S A. 2004;101:8227-32.

11.

Kojima M, Hamamoto A, Sato T. Ghrelin 0-acyltransferase (GOAT), a specific enzyme that modifies ghrelin with a medium-chain fatty acid. J Biochem. 2016;160:189-94.

12.

Taylor MS, Hwang Y, Hsiao PY, Boeke JD, Cole PA. Ghrelin O-acyltransferase assays and inhibition. Methods Enzymol. 2012;514:205-28. 
13.

Kang K, Schmahl J, Lee JM, Garcia K, Patil K, Chen A, Keene M, Murphy A, Sleeman MW. Mouse ghrelin-Oacyltransferase (GOAT) plays a critical role in bile acid reabsorption. FASEB J. 2012;26:259-71.

14.

Cummings DE, Frayo RS, Marmonier C, Aubert R, Chapelot D. Plasma ghrelin levels and hunger scores in humans initiating meals voluntarily without time- and food-related cues. Am J Physiol Endocrinol Metab. 2004;287:E297-304.

15.

Kirsz K, Zieba DA. Ghrelin-mediated appetite regulation in the central nervous system. Peptides. $2011 ; 32: 2256-64$.

16.

Hosoda H, Kojima M, Kangawa K. Ghrelin and the regulation of food intake and energy balance. Mol Interv. 2002;2:494-503.

17.

Akarsu S, Ustundag B, Gurgoze MK, Sen Y, Aygun AD. Plasma ghrelin levels in various stages of development of iron deficiency anemia. J Pediatr Hematol Oncol. 2007;29:384-7.

18.

Luke B. Nutrition and multiple gestation. Semin Perinatol. 2005;29:349-54.

19.

Natalucci G, Riedl S, Gleiss A, Zidek T, Frisch H. Spontaneous 24-h ghrelin secretion pattern in fasting subjects: maintenance of a meal-related pattern. Eur J Endocrinol. 2005;152:845-50. 20.

Kucuk N, Orbak Z, Karakelloglu C, Akcay F. The effect of therapy on plasma ghrelin and leptin levels, and appetite in children with iron deficiency anemia. J Pediatr Endocrinol Metab. 2019;32:275-80.

21.

Isguven P, Arslanoglu I, Erol M, Yildiz M, Adal E, Erguven M. Serum levels of ghrelin, leptin, IGF-I, IGFBP-3, insulin, thyroid hormones and cortisol in prepubertal children with iron deficiency. Endocr J. 2007;54:98590.

22.

Isguven P, Arslanoglu I, Erol M, Yildiz M, Adal E, Erguven M. Serum levels of ghrelin, leptin, thyroid hormones and cortisol iron deficiency IGF-I, IGFBP-3, insulin, in prepubertal children with. Endocr J. 2007;54:985-90.

23.

Akarsu S, Ustundag B, Gurgoze MK, Sen Y, Aygun AD. Plasma ghrelin levels in various stages of development of iron deficiency anemia. Journal of Pediatric Hematology Oncology. 2007;29:384-7. 24.

Dogan A, Alioglu B, Dindar N, Dallar Y. Increased Serum Hepcidin and Ghrelin Levels in Children Treated for Iron Deficiency Anemia. J Clin Lab Anal. 2013;27:81-5.

25. 
Luo QQ, Zhou YF, Chen MY, Liu L, Ma J, Zhang MW, Zhang FL, Ke Y, Qian ZM. Fasting up-regulates ferroportin 1 expression via a Ghrelin/GHSR/MAPK signaling pathway. J Cell Physiol. 2018;233:30-7. 26.

Rao J, Zhang C, Wang P, Lu L, Qian X, Qin J, Pan X, Li G, Wang X, Zhang F. C/EBP homologous protein (CHOP) contributes to hepatocyte death via the promotion of ERO1alpha signalling in acute liver failure. Biochem J. 2015;466:369-78.

27.

Luo QQ, Wang D, Yu MY, Zhu L. Effect of hypoxia on the expression of iron regulatory proteins 1 and the mechanisms involved. IUBMB Life. 2011;63:120-8.

28.

Page AJ, Slattery JA, Milte C, Laker R, O'Donnell T, Dorian C, Brierley SM, Blackshaw LA. Ghrelin selectively reduces mechanosensitivity of upper gastrointestinal vagal afferents. Am J Physiol Gastrointest Liver Physiol. 2007;292:G1376-84.

29.

Chan $\mathrm{CB}$, Cheng $\mathrm{CH}$. Identification and functional characterization of two alternatively spliced growth hormone secretagogue receptor transcripts from the pituitary of black seabream Acanthopagrus schlegeli. Mol Cell Endocrinol. 2004;214:81-95.

30 .

Wang JH, Li HZ, Shao XX, Nie WH, Liu YL, Xu ZG, Guo ZY. Identifying the binding mechanism of LEAP2 to receptor GHSR1a. FEBS J. 2019;286:1332-45.

31.

Xue Q, Bai B, Ji B, Chen X, Wang C, Wang P, Yang C, Zhang R, Jiang Y, Pan Y, et al. Ghrelin Through GHSR1a and OX1R Heterodimers Reveals a Galphas-cAMP-cAMP Response Element Binding Protein Signaling Pathway in Vitro. Front Mol Neurosci. 2018;11:245.

32.

Schrottke S, Kaiser A, Vortmeier G, Els-Heindl S, Worm D, Bosse M, Schmidt P, Scheidt HA, Beck-Sickinger AG, Huster D. Expression, Functional Characterization, and Solid-State NMR Investigation of the G ProteinCoupled GHS Receptor in Bilayer Membranes. Sci Rep. 2017;7:46128.

33.

Nakata S, Yoshino Y, Okita M, Kawabe K, Yamazaki K, Ozaki Y, Mori Y, Ochi S, Iga JI, Ueno SI. Differential expression of the ghrelin-related mRNAs GHS-R1a, GHS-R1b, and MBOAT4 in Japanese patients with schizophrenia. Psychiatry Res. 2019;272:334-9.

34.

Gnanapavan S, Kola B, Bustin SA, Morris DG, McGee P, Fairclough P, Bhattacharya S, Carpenter R, Grossman $A B$, Korbonits $M$. The tissue distribution of the mRNA of ghrelin and subtypes of its receptor, GHS-R, in humans. J Clin Endocrinol Metab. 2002;87:2988.

35 .

Anderson ER, Shah YM. Iron homeostasis in the liver. Compr Physiol. 2013;3:315-30. 36 . 
Harrison PM, Arosio P. The ferritins: molecular properties, iron storage function and cellular regulation. Biochim Biophys Acta. 1996;1275:161-203.

37.

Nemeth E, Tuttle MS, Powelson J, Vaughn MB, Donovan A, Ward DM, Ganz T, Kaplan J. Hepcidin regulates cellular iron efflux by binding to ferroportin and inducing its internalization. Science. 2004;306:2090-3.

38.

Wallace DF, McDonald CJ, Ostini L, Iser D, Tuckfield A, Subramaniam VN. The dynamics of hepcidinferroportin internalization and consequences of a novel ferroportin disease mutation. Am J Hematol. 2017;92:1052-61.

39.

Neves SP, de Carvalho NC, da Silva MM, Rodrigues A, Bomfim LM, Dias RB, Sales CBS, Rocha CAG, Soares MBP, Batista AA, Bezerra DP. Ruthenium Complexes Containing Heterocyclic Thioamidates Trigger Caspase-Mediated Apoptosis Through MAPK Signaling in Human Hepatocellular Carcinoma Cells. Front Oncol. 2019;9:562.

40.

Lu J, Li Z, Wu X, Chen Y, Yan M, Ge X, Yu J. iRoot BP Plus promotes osteo/odontogenic differentiation of bone marrow mesenchymal stem cells via MAPK pathways and autophagy. Stem Cell Res Ther. 2019;10:222.

41.

Sun Y, Liu WZ, Liu T, Feng X, Yang N, Zhou HF. Signaling pathway of MAPK/ERK in cell proliferation, differentiation, migration, senescence and apoptosis. J Recept Signal Transduct Res. 2015;35:600-4. 42.

Liu M, Fan F, Shi P, Tu M, Yu C, Yu C, Du M. Lactoferrin promotes MC3T3-E1 osteoblast cells proliferation via MAPK signaling pathways. Int J Biol Macromol. 2018;107:137-43.

43.

Waseem T, Duxbury M, Ashley SW, Robinson MK. Ghrelin promotes intestinal epithelial cell proliferation through PI3K/Akt pathway and EGFR trans-activation both converging to ERK $1 / 2$ phosphorylation. Peptides. 2014;52:113-21.

44.

Mazzocchi G, Neri G, Rucinski M, Rebuffat P, Spinazzi R, Malendowicz LK, Nussdorfer GG. Ghrelin enhances the growth of cultured human adrenal zona glomerulosa cells by exerting MAPK-mediated proliferogenic and antiapoptotic effects. Peptides. 2004;25:1269-77.

\section{Table 1}

Table 1 Primer Sequences 


\begin{tabular}{lc}
\hline Name (mouse species) & Primers used in PCR (from 5' to 3') \\
\hline ghrelin forward & TCCAAGAAGCCACCAGCTAA \\
ghrelin reverse & AACATCGAAGGGAGCATTGA \\
GHSR1a forward & CTATCCAGCATGGCCTTCTC \\
GHSR1a reverse & AAGACGCTCGACACCCATAC \\
GOAT forward & ATTTGTGAAGGGAAGGTGGAG \\
GOAT reverse & CAGGAGAGCAGGGAAAAAGAG \\
hepcidin forward & GCACCACCTATCTCCATCAACA \\
hepcidin reverse & TTCTTCCCCGTGCAAAGG \\
b-actin forward & AAATCGTGCGTGACATCAAAGA \\
b-actin reverse & GCCATCTCCTGCTCGAAGTC \\
\hline
\end{tabular}

\section{Figures}

A

mRNA:

C

mRNA:
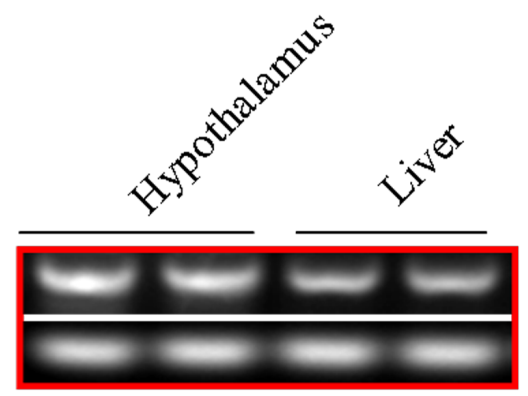

GHSR $1 \alpha$ $\beta$-actin

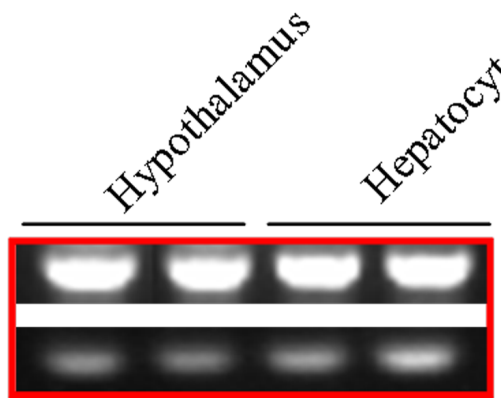

B

Protein:

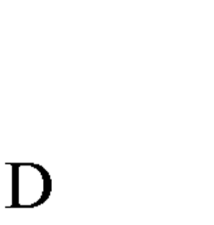

Protein:
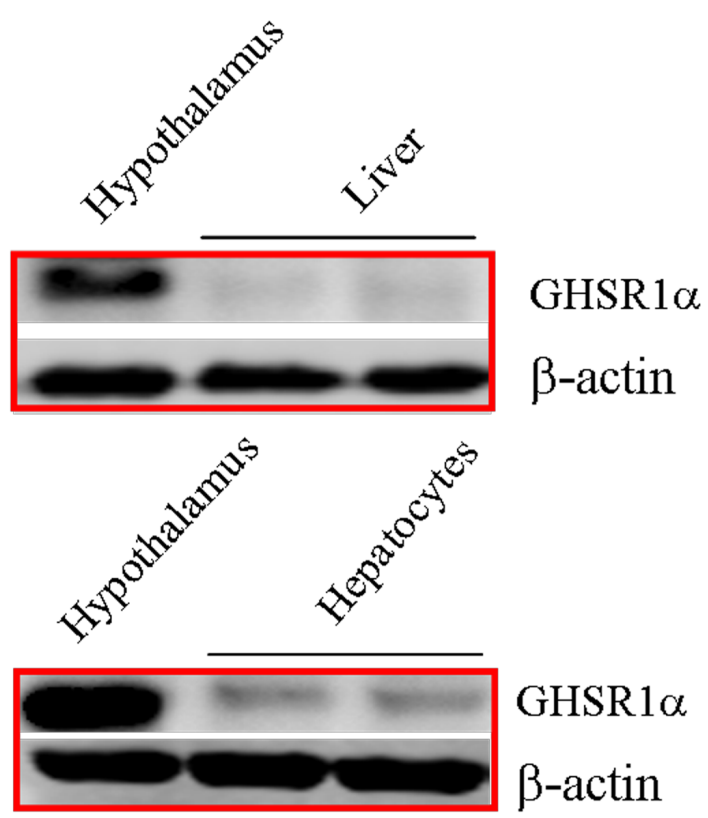

GHSR $1 \alpha$

\section{Figure 1}

mRNA and protein expression of GHSR1a in the liver and hepatocytes. Expression of GHSR1a mRNA and protein ( $\sim 4 \mathrm{kD})$ in hypothalamus (the positive control) and liver (A, B), hepatocytes (C, D) in wild mice was determined by qRT-PCR and Western blot analysis as described in Materials and Methods section. 

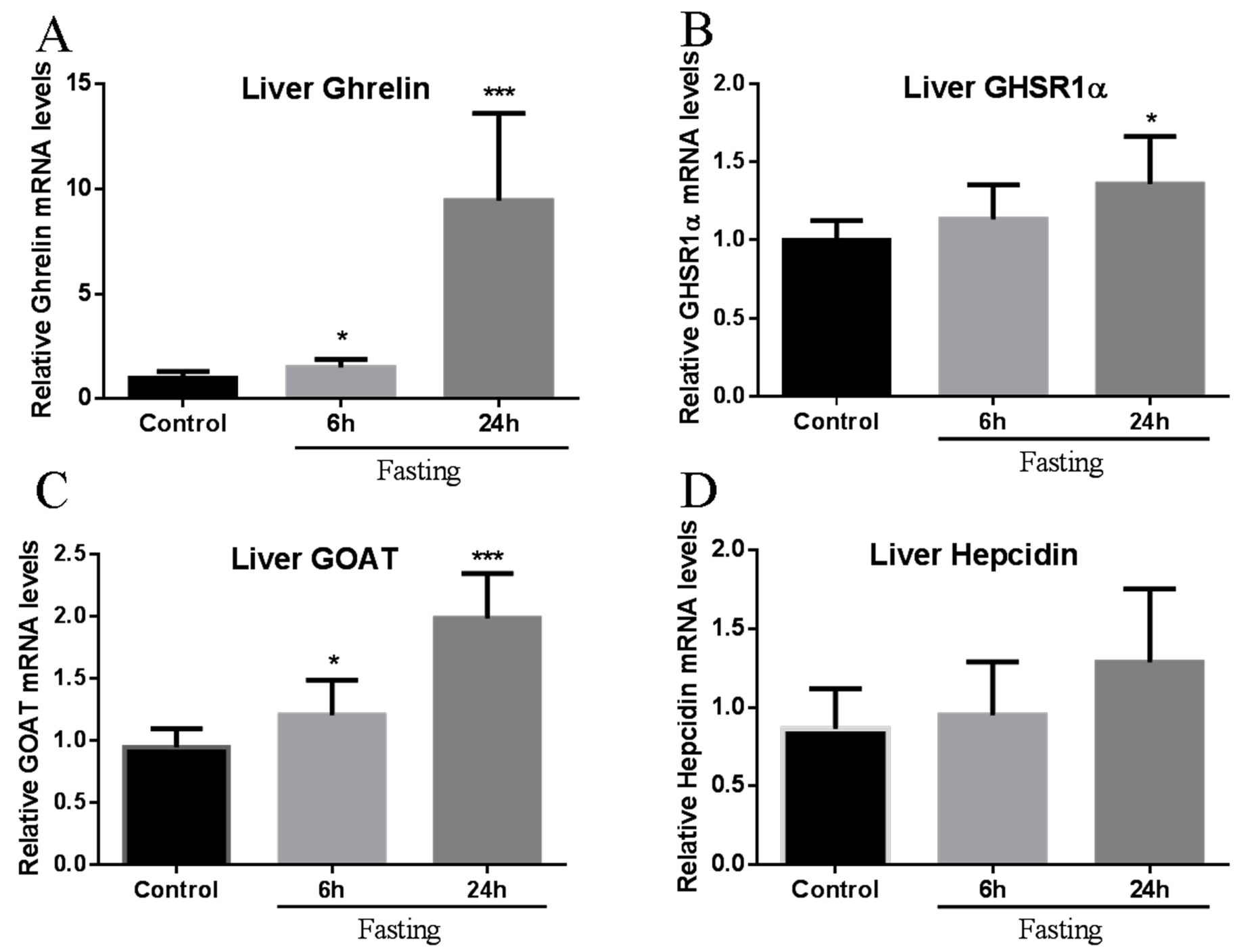

Figure 2

The mRNA expression of total ghrelin, GOAT, and GHSR1a in the liver was induced significantly after fasting. The total ghrelin (A), GHSR1a (B), GOAT (C), and hepcidin (D) mRNAs in mouse liver were tested by q-PCR before fasting (control) and after fasting for 6 or $24 \mathrm{hr}$. The relative mRNA expression was relative to $\beta$-actin. Data are presented as the mean $\pm S D(n=7) .{ }^{\star} p<0.05,{ }^{* \star} p<0.001$ versus control. 


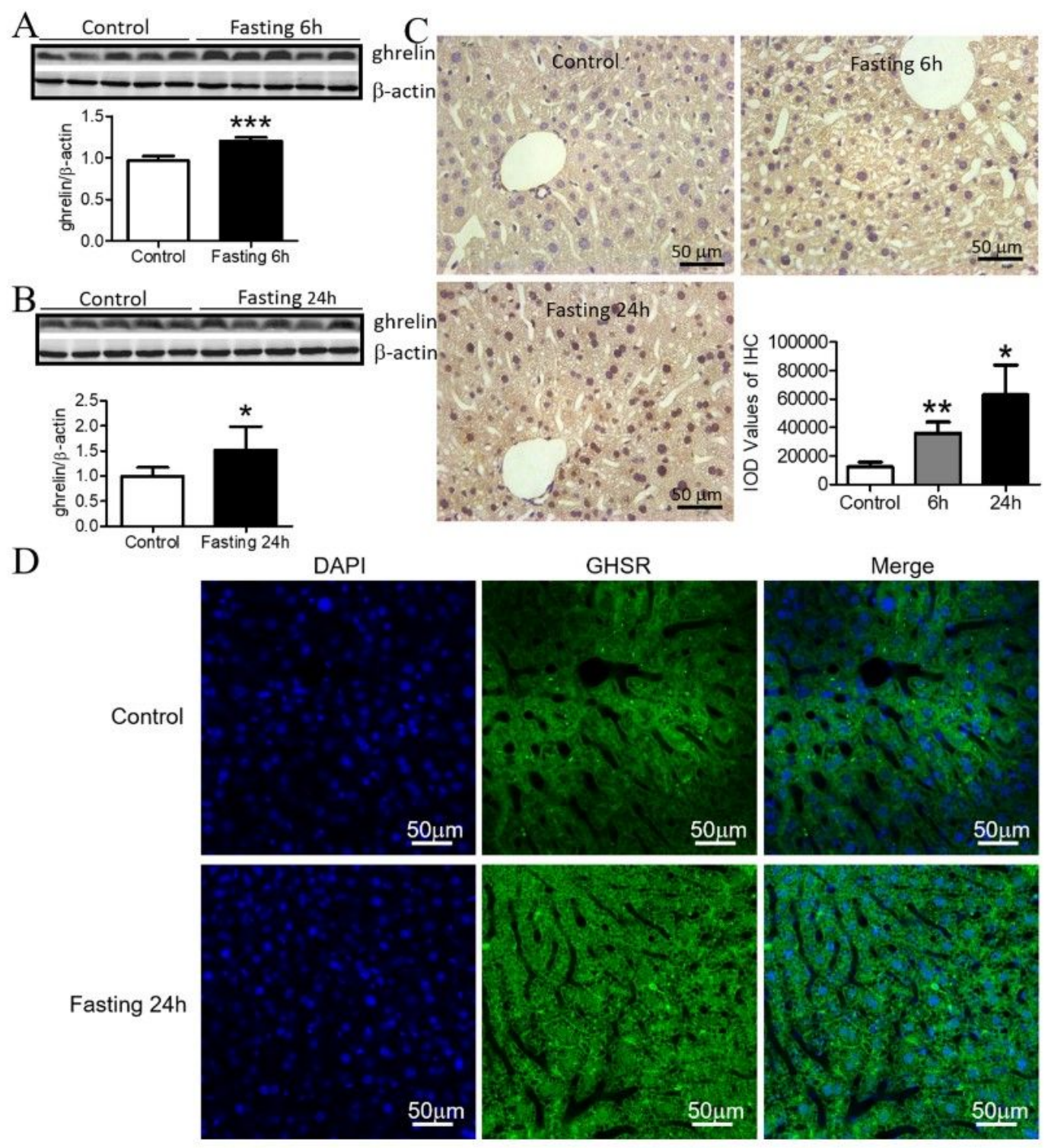

\section{Figure 3}

Fasting significantly increased the total protein expression of ghrelin in mouse liver. The total ghrelin level in mouse liver was detected by Western blotting (A, B) and IHC (C) before (the control) and after 6 or $24 \mathrm{hr}$ of fasting. The GHSR1a distribution in the liver was detected using IF (D) before (the control) and after 6 or $24 \mathrm{hr}$ of fasting as described in the Materials and Methods section. Data are presented as the mean \pm SD $(n=5) .{ }^{*} p<0.05,{ }^{*} p<0.01$, and ${ }^{* \star *} p<0.001$ versus control. 
A
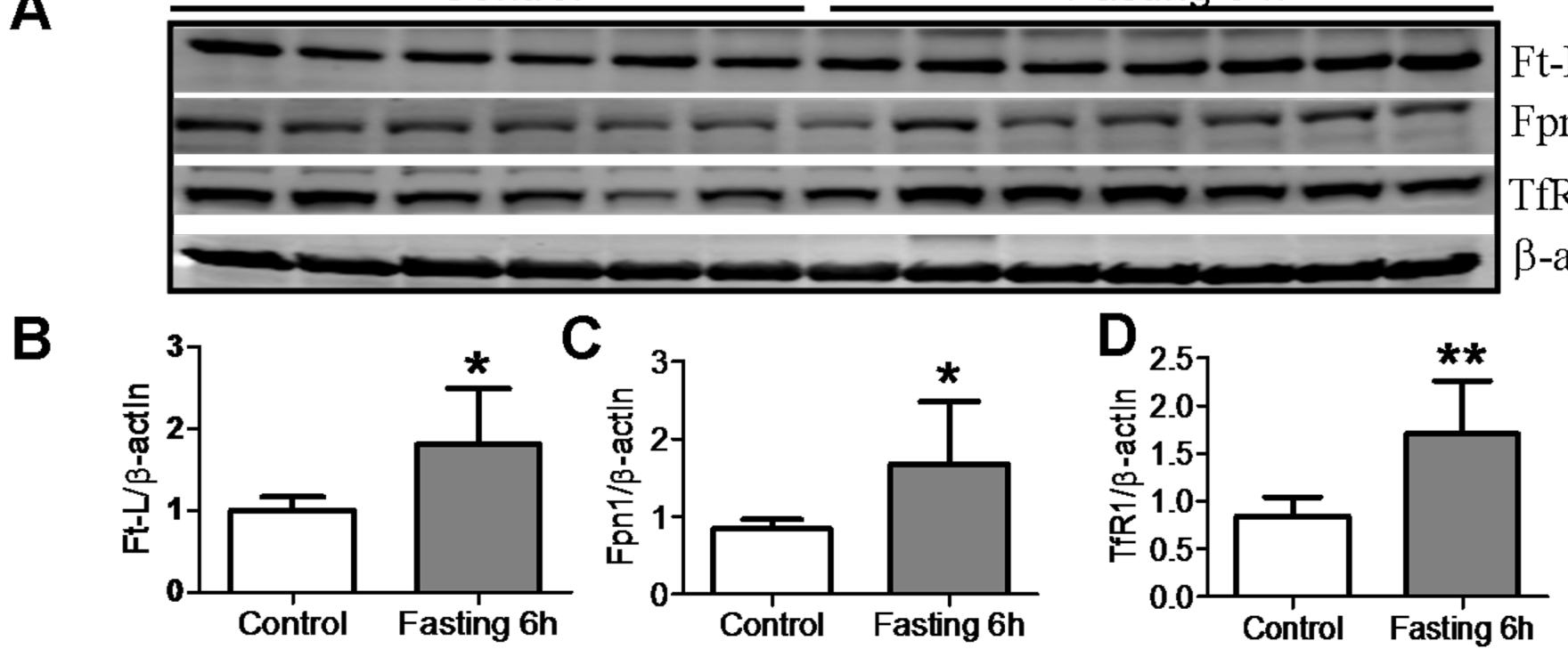

E

Control

\section{Fasting 24h}

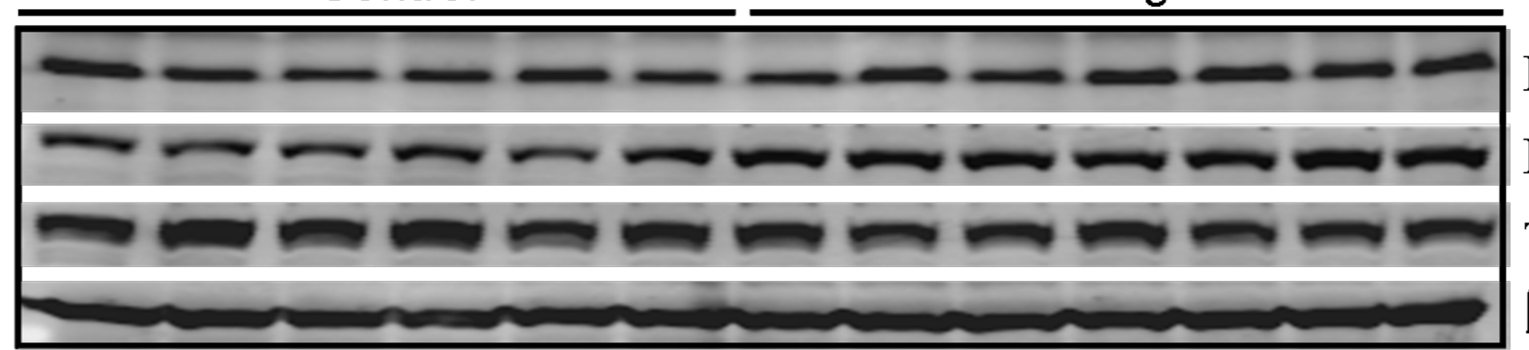

Ft-L

Fpn1

TfR1

$\beta$-actin
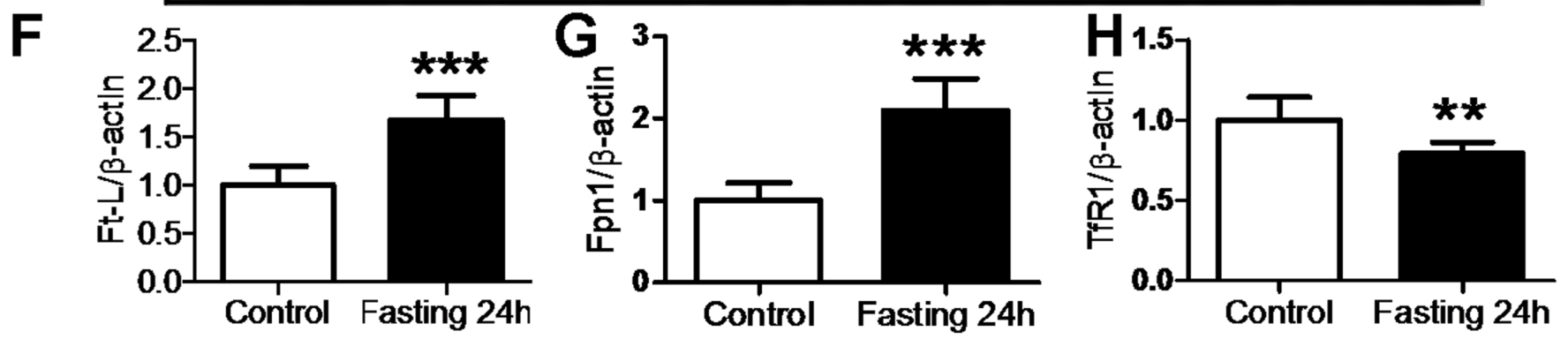

Figure 4

Fasting significantly increased the protein expression of Fpn 1 and Ft-L in the liver. The protein levels of Ft-L (B, F), Fpn1 (C, G), and TfR1 (D, H) in mouse liver were measured by Western blotting before fasting (control) and after fasting for $6(A)$ or $24 \mathrm{hr}(B)$. Data are presented as the mean $\pm S D(n=6 \sim 7)$. ${ }^{*} p<0.05$, $\star \star p p<0.01$, and $* * * p<0.001$ versus control. 

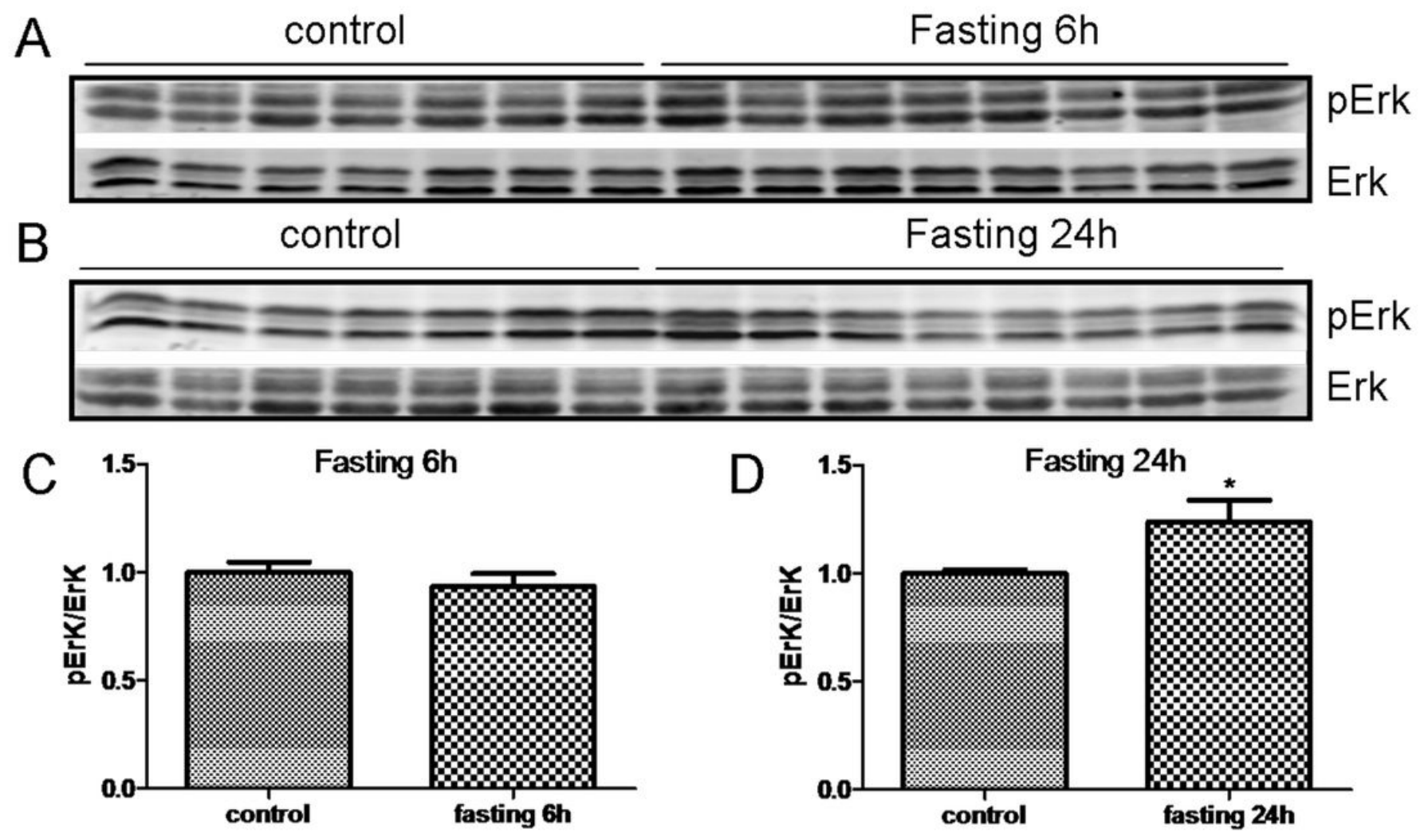

Figure 5

Fasting significantly enhanced ERK phosphorylation in the liver after fasting for $24 \mathrm{hr}$. The expression of pERK in mouse liver was detected by Western blotting before (the control) and after $6(A, C)$ or $24 \mathrm{hr}(\mathrm{B}, \mathrm{D})$ of fasting as described in the Materials and Methods section. Data are presented as the mean \pm SD $(n=$ 7 8). ${ }^{*} p<0.05,{ }^{*} p<0.01$, and ${ }^{* *} p<0.001$ versus control. 
A

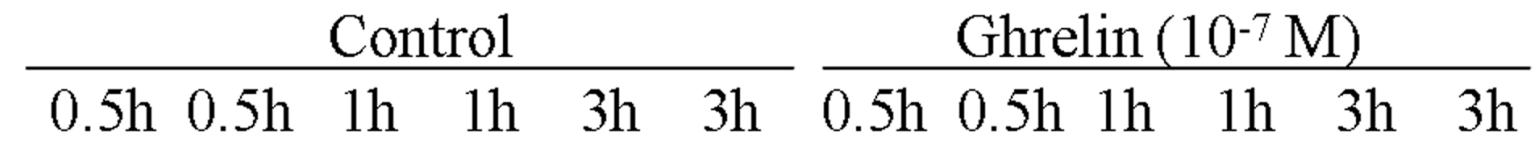
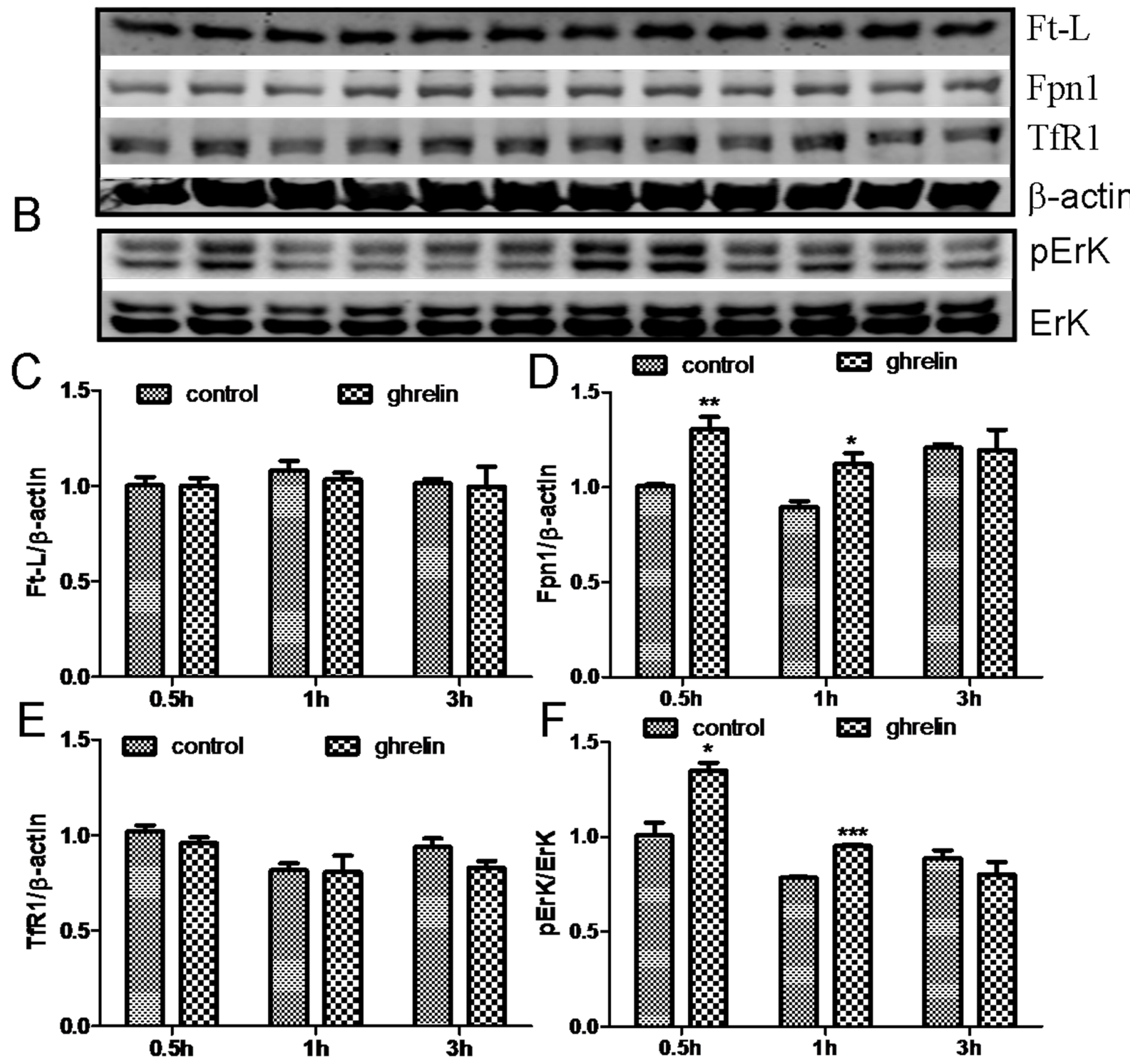

Figure 6

Ghrelin significantly increased the expression of Fpn1 but had no effect on Ft-L and TfR1 protein expression in hepatocytes in vitro. The expression levels of Ft-L (A, C), Fpn1 (A, D), TfR1 (A, E), ERK and pERK $(B, F)$ protein in hepatocytes treated with $0.1 \mu \mathrm{M}$ ghrelin for $0.5,1$, and $3 \mathrm{hr}$ were measured by Western blot analysis. Data are presented as the mean \pm SD $(n=6 \sim 7) .{ }^{\star} p<0.05,{ }^{\star \star} p<0.01$ versus control. 
A control ghrelin Inhibitor Inhibitor+ghrelin

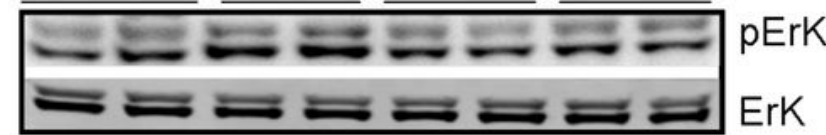
B

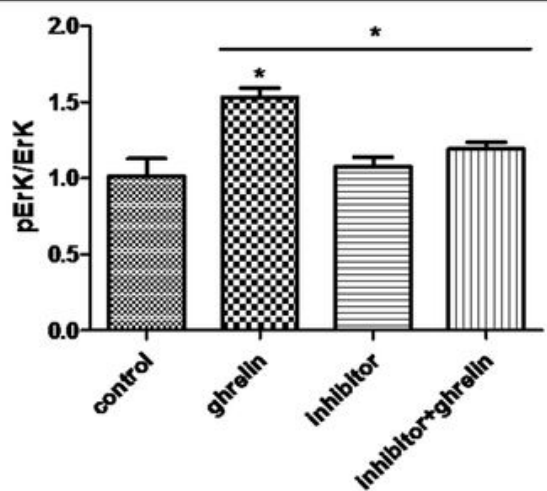

C control ghrelin Inhibitor Inhibitor+ghrelin

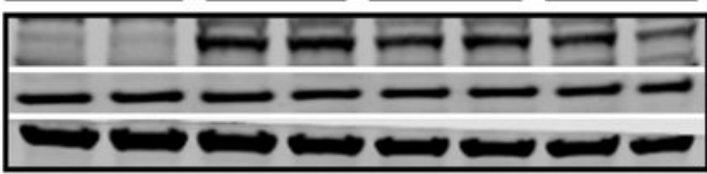

D

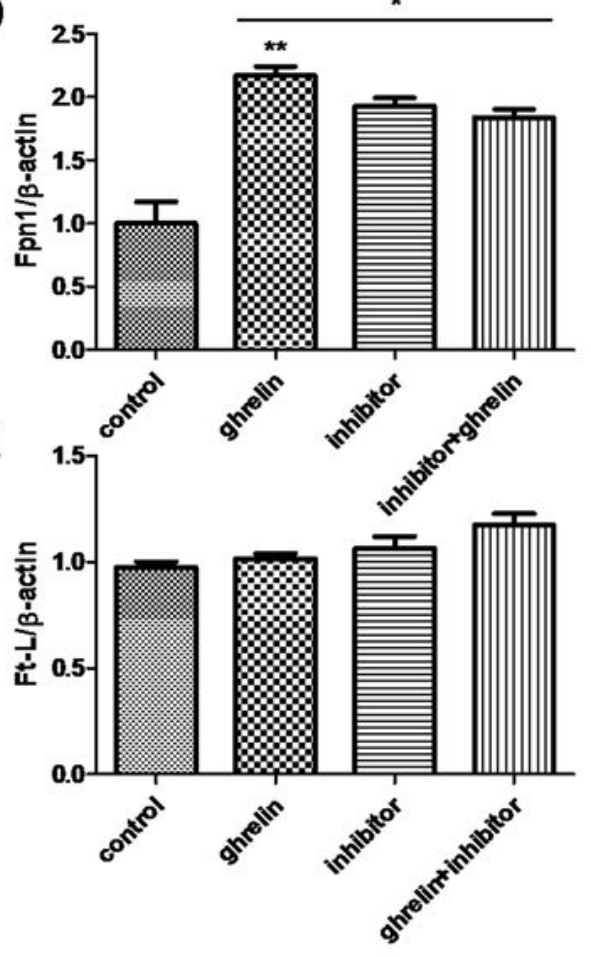

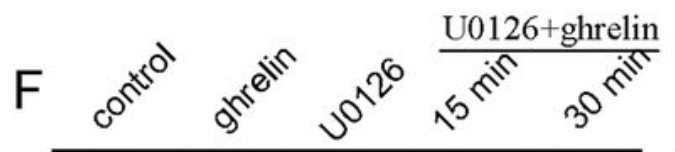
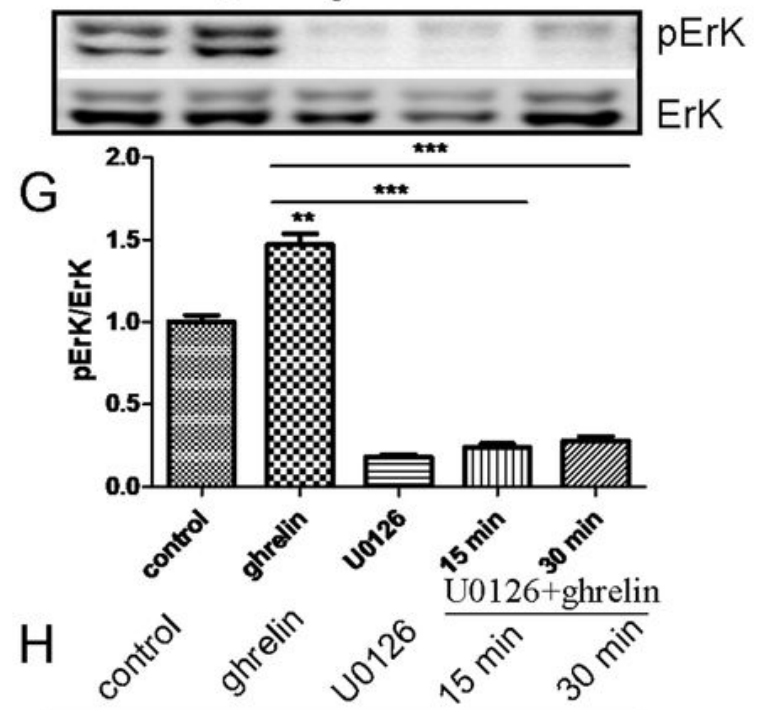

Fpn1
Ft-L
$\beta$-actin

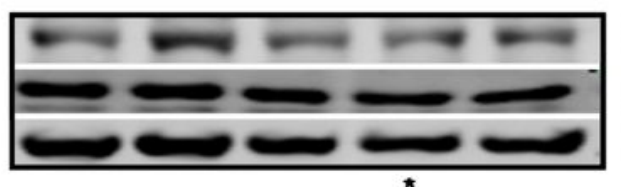

Fpn1

$\mathrm{Ft}-\mathrm{L}$

$\beta-$ actin
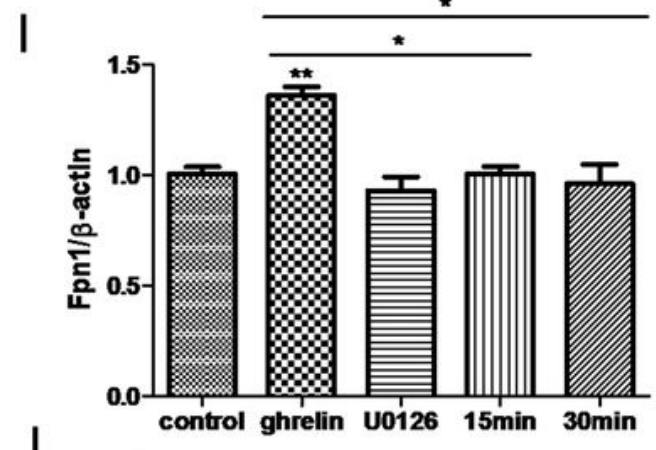

J

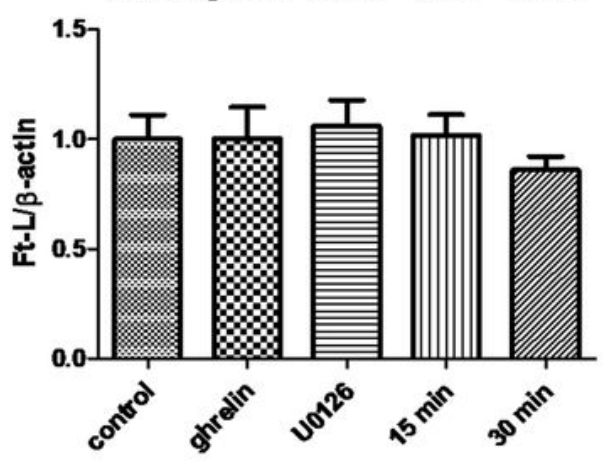

Figure 7

GSHR1 a inhibitor D-(lys-3)-GHRP-6 or pERK inhibitor (U0126) significantly suppressed ghrelin-induced Fpn1 upregulation in hepatocytes, while Ft-L and TfR1 were not affected by ghrelin. Hepatocytes were pretreated with $100 \mathrm{nM}$ D-(lys-3)-GHRP-6 for $1 \mathrm{hr}$ or $10 \mu \mathrm{M}$ U0126 for $6 \mathrm{hr}$, followed by treatment with ghrelin (10-7 M) for another $0.5 \mathrm{hr}$. The phosphorylation of ERK ( $A$ and $B, F$ and $G$ ) and the expression of 
Fpn1 ( $\mathrm{C}$ and $\mathrm{D}, \mathrm{H}$ and $\mathrm{I}$ ) and Ft-L ( $\mathrm{C}$ and $\mathrm{E}, \mathrm{H}$ and $\mathrm{J}$ ) were detected by Western blotting. Data are presented as the means $\pm S D(n=3) .{ }^{*} p<0.05,{ }^{* *} p<0.01$, and ${ }^{* *} p<0.001$ versus control. 